\title{
A Editora do Brasil S/A nos anos 1960-1970: a consolidação de uma editora brasileira no mercado didático e o ensino de educação moral e cívica
}

\author{
Katya Mitsuko Zuquim Braghini*
}

\begin{abstract}
Resumo:
Por meios da análise de fontes diversas, apresentamos um histórico da Editora do Brasil S/A, editora brasileira, familiar, surgida em 1947, que passou por um surto de crescimento nos anos 1960, para figurar, no início dos anos 1970, como uma das mais importantes editoras do país. Essa análise aponta para o alinhamento da editora com o regime militar, tanto em discursos, que denotavam a disposição da editora em defender o fechamento das liberdades civis, quanto pelas práticas, já que os seus editores mantinham relacionamento com grupos, civis e militares, interessados no retorno da disciplina de educação moral e cívica (EMC) ao currículo escolar, fato este que muito contribui para o fortalecimento da Editora no mercado didático.
\end{abstract}

\section{Palavras-chave:}

história das editoras; história do livro didático; história das disciplinas escolares; mercado editorial; ditadura militar.

* Professora do PEPG em Educação: História, Política, Sociedade (EHPS-PUC/SP). Doutora em Educação pelo mesmo programa. Pós-doutoranda do Grupo de Estudos e Pesquisas em História da Educação (GEPHE) da Faculdade de Educação da Universidade Federal de Minas Gerais (UFMG). 


\title{
Editora do Brasil S/A in the 1960s and 70s: the consolidation of a publishing house in the textbook market and the teaching of moral and civic education
}

\author{
Katya Mitsuko Zuquim Braghini
}

\begin{abstract}
:
Through the analysis of several sources, we present the history of 'Editora do Brasil S/A', a family owned Brazilian publishing house established in 1947, that experienced fast growth in the 1960s and became one of the most important publishing houses of the country in the early 70s. This analysis points to the alignment of the publishing house with the military regime, both in its discourses, which indicated its intention to defend the shutdown of civil freedom, as well as through its practices, since their editors kept relations with civil and military groups interested in having the subject moral and civic education back into the school syllabus, contributing to the strengthening of the publishing house in the textbook market.
\end{abstract}

Keywords:

publishing house history; textbooks; school subject history; publishing industry; military regime. 
Nos anos 1960, a Revista da Editora do Brasil S/A (EBSA), revista periódica, educacional, mensal, transmitiu a impressão de que a riqueza tinha chegado à editora, principalmente após 1964. Se, por um lado, o patrimônio foi construído com o trabalho árduo de seus membros, o que era constantemente reiterado nas páginas dessa Revista, por outro, as evidências demonstraram que esse sucesso também, se deu por conta do alinhamento da editora ao regime militar.

Esse alinhamento, percebido nos discursos da Revista, era tanto de ordem ideológica, por conta das posições políticas tomadas e pelas orientações educacionais dadas aos leitores, quanto de ordem prática, ou seja, pelas relações estabelecidas entre os membros da editora e os grupos específicos, que serão apresentados ao longo do artigo, os quais contribuíram com a demarcação do timbre da Editora do Brasil no mercado editorial.

É a intenção deste artigo apontar como o retorno da disciplina de educação moral e cívica (EMC) à rotina escolar fortaleceu a posição da Editora do Brasil no mercado editorial didático brasileiro durante o período da ditadura militar. Analisaremos os artigos publicados na já citada Revista da Editora do Brasil S/A (EBSA), periódico da própria editora, seu principal porta-voz e veículo difusor das ideias e planos do grupo em análise. Soma-se a este conjunto documental a legislação pertinente ao tema, documentos encontrados em diversos cartórios da cidade de São Paulo, na Junta Comercial do Estado de São Paulo, Biblioteca do Livro Didático da Faculdade de Educação da Universidade de São Paulo (FE-USP), entre outros.

Para tanto, o artigo está separado em três frentes. A primeira apresenta brevemente o surgimento da editora, anunciando os nomes dos sujeitos que constituíram a sua história. Depois, registramos o relacionamento dos membros da editora com pessoas e grupos interessantes ao desenvolvimento do nome da empresa frente ao mercado editorial. Falamos, principalmente, dos contatos entre os editores e agentes com o poder de decidir sobre o regresso da disciplina EMC na escola. Analisamos o mercado didático brasileiro no período da ditadura militar, apresentando o alinhamento, de ideias e práticas, entre os membros da editora e os indivíduos responsáveis pelas prescrições educacionais no ambiente governamental. Pretende-se participar do debate sobre a atuação de civis, durante esse período traumático da história do nosso país. 


\section{A fundação da Editora do Brasil S/A}

O nascimento da sociedade anônima Editora do Brasil está ligado a um fato ocorrido em outra editora de livros didáticos. De acordo com Hallewell (1985, p. 289), em 1943, a Companhia Editora Nacional perdeu seis de seus funcionários, professores, "[...] que respondiam pela execução de livros didáticos, deixaram a empresa para estabelecer a sua própria editora [...]". Três desses demissionários partiram para a fundação de outra editora: Carlos Costa, Carlos Pasquale, Manoel Netto.

De acordo com Neves (2005), a Editora do Brasil foi pensada, em primeiro lugar, pelas vontades de Carlos Costa e Manoel Netto, quando esses ainda eram, respectivamente, autor (de livros didáticos de Biologia) e funcionário (editor assistente) da Companhia Editora Nacional. Segundo a autora, Manoel Netto teria aceitado o convite de Carlos Costa para, juntos, formarem uma nova editora (NEVES, 2005, p. 62-63) ${ }^{1}$.

O sítio eletrônico da Editora do Brasil apresenta Carlos Costa como o fundador da empresa, "[...] principal e maior acionista [...]", "[...] médico de formação [...]", "[...] autor de sucesso com livros publicados nas áreas de Química e Biologia [...]”. De acordo com o histórico registrado no sítio, esse homem se associou com "outros autores", para "juntos" começarem "[...] um trabalho consciente que visava oferecer textos de qualidade por um preço justo" ". Esse professor era o maior acionista de ações nominativas da empresa editora, com direito de voto nas assembleias (JUNTA..., 1943, p. 18, 23). Foi professor do colégio pré-universitário da Universidade de São Paulo.

No dia 5 de agosto de 1943, foi registrada no $11^{\circ}$. Tabelionato de São Paulo a constituição da sociedade anônima sob a denominação de Editora do Brasil S/A, com o objetivo de "[...] edição e divulgação de obras didáticas e de caráter cívico de real valor" (JUNTA..., 1943, p. 10). Na ficha de breve relato completa, no documento que registra o nascimento da editora na

1 São livros dos autores: Chimica para a $3^{a}$. série (ensino secundário); Chimica para a $4^{a}$. série (ensino secundário); Chimica para a $5^{a}$. série (ensino secundário). De Carlos Costa: História natural - $2^{a}$ série do curso cientifico (ensino secundário); Elementos de física, química e história natural: para o curso propedêutico das escolas de comércio (ginasial). Disponível em: <http://paje.fe.usp.br/estrutura/livres/index.htm>. Acesso em: 3 mar. 2008.

2 Texto disponível na internet: <http://www.editoradobrasil.com.br/index $>$. Acesso em: 04 nov. 2006. 
Junta Comercial está a indicação de que a empresa cuidava da "[...] edição e comércio de livros; indústria e comércio de papéis e artes gráficas"3.

Entre os trinta e seis membros fundadores, podemos constatar a presença de alguns professores da capital e do interior, funcionários públicos e membros atuantes na política de São Paulo, por exemplo, Alfredo Leite Gomes, autor de livro didático pela Companhia Editora Nacional; Joaquim de Campos Bicudo, inspetor federal de ensino; Otto Costa, advogado e, posteriormente, procurador geral do Estado de São Paulo (1966-1969) (JUNTA..., 1943, p. 21-23).

A formalização da sociedade anônima se deu por meio da união de algumas famílias, já que o documento apresenta alguns sobrenomes repetidos. Esse é o caso das famílias Costa; Pinto e Silva; Terreri; Bicudo e Campos Bicudo; Piza e Toledo Piza.

Mas eram as famílias Costa e Netto que figuravam como membros mais atuantes no interior da editora. As famílias Costa e Netto foram fundadoras da editora e estabeleceram uma união que ultrapassou gerações. Os nomes Costa e Netto estavam relacionados à parte administrativa da empresa, mas ambos tinham a sua presença pairando por todos os procedimentos da produção de livros e materiais editoriais. Eram eles que respondiam pela editora 4 .

Os membros da família Costa apareciam em EBSA como as maiores personalidades do nome jurídico. Na fundação da empresa, Fernando Costa foi indicado como diretor-presidente da sociedade anônima. Ele morreu em 1960 e foi substituído por Carlos Costa, e este permaneceu no cargo até $1996^{5}$.

3 A ficha de breve relato completa consiste em um extrato, cujo teor contém listados e enumerados todos os documentos referentes a uma determinada empresa que pede a guarda da documentação na Junta Comercial de São Paulo.

4 As famílias Costa e Netto trilharam um longo percurso nos quadros da diretoria da empresa, ultrapassando gerações. Depois da saída de Carlos Costa, em 1996, vários membros da família Costa assumiram os cargos de direção. Isso também aconteceu com Manoel Netto (JUNTA..., 2007, p. 3-4,13).

5 Os membros das famílias foram autores de livros pela Editora do Brasil. Aída Costa e Renato Pasquale foram nomes citados no catálogo em 1949, com livros para a disciplina português: o livro Português para admissão ao ginásio (série ginásial); Português prénormal, (série normal); e, por fim, os volumes para as quatro séries do curso comercial. Posteriormente, outro membro da família Costa assinará como autor de livros didáticos dentro da Editora do Brasil. Trata-se de Otto Costa, autor do livro Moral e civismo, publicado nos anos 1970, em conjunto com Victor Mussumeci e Felipe Moschini. Otto Costa também figura como membro fundador da editora, na ata de constituição da sociedade anônima em 1943. (JUNTA... 1943, p. 21-23). 
Manuel Netto iniciou a sua carreira na nova editora como diretorgerente. Ele foi um importante funcionário, dirigindo a seção industrial da editora, além de ser responsável pelos termos de abertura e encerramento de livros, assinatura de correspondências. Depois, Netto se tornou diretorsuperintendente e passou a promover contratos e distratos com os autores, além de ocupar uma espécie de vice-presidência.

O período em que Fernando Costa era o diretor-presidente (1943-1960) foi o momento em que a Editora do Brasil passou a se promover com a intenção de fixar o seu nome no mercado de livros. Para isso, os seus diretores se organizaram em torno de três ideias: montar um catálogo de livros didáticos; promovê-lo por meio de técnicas variadas; lançar uma Revista da própria editora.

Em 1949, a Editora do Brasil possuía dois catálogos: um de livros didáticos (Coleção didática do Brasil), e outro de livros de leitura (Coleção infantojuvenil). A lista de livros didáticos tinha 70 autores, compreendendo todas as disciplinas obrigatórias para o ensino secundário (ginasial e colegial). Já o catálogo da coleção infantojuvenil contava com 23 autores, misturando autores da literatura mundial e autores brasileiros. O catálogo foi constituído por autores que migraram da Companhia Editora Nacional (Alfredo Gomes, Carlos Costa, Carlos Pasquale, Rui Ribeiro Couto), associados a nomes que lançaram livros por essa editora e nela permaneceram por vários anos. Esses são os casos de Victor Mussumeci, Aída Costa e Fernando Furquim, este último, considerado pelos diretores como um "sucesso editorial".

\section{A Editora do Brasil nos anos 1960, o seu mercado editorial didático e o retorno da disciplina de educação moral e cívica (EMC)}

Ao longo da década de 1960, os editores passaram a valorizar os artigos publicados em jornais diários, fazendo uma seleção de assuntos que eles julgavam de interesse dos seus leitores, transformando a sua revista periódica mensal em clipping daquilo que eles consideravam os assuntos mais importantes do mês. Desse modo, foram vários os órgãos de imprensa citados na Revista, como fontes de informação, em sua seção Opiniões do 
$m e s^{6}$. Da parte dos editores, havia uma tendência anticomunista evidente; eram claros ao apontar o descontentamento com a mobilização estudantil, não demonstravam simpatia pelo governo de João Goulart.

Um dos nomes de maior destaque em EBSA era do jornalista e teórico católico Gustavo Corção. Conhecido por defender uma ética social católica em seus escritos nos jornais, esse jornalista tinha por opinião que a política era função de uma "elite de bem". Essa elite deveria se ocupar da manutenção de um equilíbrio que fosse avesso aos excessos e aos riscos de uma ordem social mantida pela multidão. A “elite de bem” era gente que já nascia com um espírito político e que não colocava interesses econômicos à frente dos interesses do bem comum (SILVA, 2004).

As ideias de Gustavo Corção ajustavam-se com os parâmetros da editora, tanto por conta dos discursos anticomunistas, quanto pelo fato de elas terem a essência das posições mantidas pelos diretores da Editora do Brasil. Posicionar-se entre uma elite que tentava demonstrar desprezo pelos interesses econômicos, mas que assumia a sua própria prosperidade como um reflexo do progresso do Brasil era o mote de trabalho. Segundo o que era divulgado pelos artigos, o posicionamento voltado ao catolicismo, vai supostamente ao encontro dos ideais mantidos por uma parcela do público leitor, que eram os professores e funcionários de escolas confessionais.

Os editores assumiam um compromisso com os católicos adeptos da causa da depuração do Brasil. Ignoravam a posição de religiosos "comunistas" e não necessariamente apoiavam uma ala de "esquerda", que surgia na Igreja nos anos 1960. Por isso, optavam por manter-se fiéis aos escritos de D. Vicente Scherer, conhecido à época, entre outros assuntos, por atacar Anísio Teixeira, acusando-o de "comunista", por conta da participação do educador baiano na campanha em defesa da escola pública.

O vínculo da Editora do Brasil com os militares e com esse posicionamento católico conservador foi reforçado em julho de 1967, com a entrada do professor Alfredo Gomes nos quadros de funcionários da Editora do Brasil. De acordo com Costa (1977, p. 3), o docente foi trazido à editora pelas mãos

6 Foram contabilizados 82 artigos vindos da imprensa diária, dentro de um lote de 211 artigos. Os jornais mais utilizados para a transcrição de artigos foram: $O$ Estado de S. Paulo (18), Diário de Notícias (10), Jornal do Brasil (10), O Globo (8), Jornal do Comércio (7), Diário de S. Paulo (5), O Jornal (5), entre outros. 
de Carlos Pasquale e foi um árduo defensor das ideias propugnadas pela Ação Católica, tendo a prosperidade de uma "vanguarda intelectual católica" como parte de sua política ${ }^{7}$.

Aliás, o apego aos ideais católicos por parte da editora ficou claro por conta de três evidências: a ampla defesa da expansão do ensino secundário privado em conjunto com os colégios católicos; o número de colégios católicos para os quais se voltou a divulgação da editora; e a defesa apaixonada em prol da educação católica ${ }^{8}$. Isso, descontados os relacionamentos que o próprio Alfredo Gomes e o seu colega Victor Mussumeci mantinham com os clérigos, autores de livros didáticos, membros das Comissões Nacional e Regional de Moral e Civismo, diretores de escolas e representantes de editoras católicas, como veremos logo adiante.

Além disso, havia um compartilhamento de ideias muito afinado entre a divulgação editorial deste grupo empresarial e o que estava contido na declaração Gravissimum Educationis, aprovada em 28/10/1965 durante o Concílio Vaticano II, em que foram tratados vários temas sobre a educação. O título deste documento apontava para a "Importância da educação", dando ênfase a uma educação cristã, dada, principalmente, em escolas católicas, diante de assuntos relacionados à moral e à ciência. No entanto, havia o apelo dos bispos para que uma "educação cristã" não ficasse restrita às escolas católicas. O documento indicava que "educadores" eram os pais, a sociedade civil e a Igreja e que, portanto, juntos, deviam "fazer promover os vários modos de educação da juventude". Não se trata aqui de dizer que as resoluções do Concílio Vaticano II estavam diretamente relacionadas com a política educativa do regime militar brasileiro. Seguindo as evidências

7 É necessário dizer que, para os editores, o golpe militar, chamado por eles de "Revolução", não foi noticiado pela revista EBSA. As notícias posteriores já apresentavam o novo governo instituído. Além disso, havia a prática do grupo de criar um consenso quando se pensava em "militares". Os editores, até por desconhecimento, ignoravam a presença de militares legalistas, e até mesmo comunistas, dentro das Forças Armadas.

8 Dos 318 colégios listados na pequena amostra feita a partir da seção "Correspondência" da Revista, entre 1947-1961, não foi possível afirmar, com precisão, quantos eram os colégios confessionais que escreviam para a Revista. Alfredo Gomes, autor de livros didáticos, migrado da Companhia Editora Nacional, católico fervoroso, não se intimidava em escrever em seus artigos: "[...] júbilo pelo nascimento do Salvador [...]", o "Cristo Senhor que, em Si mesmo, trazia a mais importante de todas as mensagens [...]": "Glória a Deus nas alturas, e paz na terra aos homens de boa vontade [...]" (EDITORA..., 1972, p. 3). 
documentais, afirmamos que o apelo voltado a um trabalho conjunto entre pais, sociedade civil e Igreja foi prontamente atendido pelo redator-chefe da empresa, já que a Editora do Brasil esteve disposta a incluir textos em nome dessa tríplice relação social ${ }^{9}$.

Alfredo Gomes esteve "[...] à frente de campanhas em prol do restabelecimento da disciplina de Moral e Cívica nos currículos escolares [...]", durante o período de sua atuação na Comissão Estadual de Moral e Civismo em São Paulo e foi membro efetivo do Conselho Estadual de Educação, presidindo a Comissão Dinamizadora do Ensino Religioso, Social, Moral e Cívico, “[...] instituída na Secretaria da Educação [...]” (GOMES, 1969, p. 6).

Dentro da Editora do Brasil, essa campanha deu margem à elaboração e produção de livros didáticos de educação moral e cívica e de congêneres: organização social e política brasileira (OSPB) e estudos dos problemas brasileiros (EPB), e, como diz Filgueiras (2006), deu um fruto pioneiro, antes mesmo de 1964. Trata-se do livro de Victor Mussumeci, um dos primeiros livros de OSPB publicado no país. É possível sugerir, portanto, que a Editora do Brasil já havia se preparado para os trâmites que seriam apresentados pela Indicação n ${ }^{\circ} 1$ de 1962 do Conselho Federal da Educação, cujo teor propunha a prática educativa da educação cívica. No mesmo ano, houve a criação da disciplina OSPB para o ensino secundário "[...] como parte complementar do currículo escolar para o ciclo ginasial [...]” (FILGUEIRAS, 2006, p. 37). Talvez, não por coincidência, o livro de Mussumeci, no ano seguinte, já estivesse em sua $23^{\mathrm{a}}$ edição ${ }^{10}$.

Os membros da editora, como já apontamos, mantiveram contato direto com os militares responsáveis pelas ordenações educacionais. Mas, antes de apresentar a relação dos responsáveis pela editora com os militares, será necessário explicar algumas particularidades da rotina da editora. Na Revista, era normal a transcrição de textos produzidos na caserna (EDITORA..., 1964, p. 1-2). Também eram publicados comunicados sobre eventos e artigos organizados por militares, preferencialmente generais, preocupados com a educação do país e, mais precisamente, ocupados com o processo de instituição da disciplina educação moral e cívica, nos currículos escolares

9 "Declaração Gravissimum Educationis sobre a educação cristã" está disponível no site do Vaticano: <http://www.vatican.va/archive/> .

10 Referência retirada do Banco de Dados Livres e da Biblioteca do Livro Didático da Faculdade de Educação da Universidade de São Paulo: MUSSUMECI, Victor. Organização social e política brasileira. 23. ed. São Paulo: Editora do Brasil, 1963. 
do país. Nas páginas do periódico, foi constatado um zelo excessivo pela manutenção de contatos pessoais que estivessem ligados a essa temática.

Antes mesmo dos anos 1960, em 1953, a Revista já demonstrava em suas Crônicas do mês a inquietação do General Juarez Távora com relação à falta de civismo nas escolas. De acordo com o conteúdo, as palavras do general eram "muito objetivas e oportunas", mereciam "ser meditadas". O general Távora reclamava sobre o ensino da "moral" aplicado nas escolas, que devia ser aprimorado "[...] pela elevação dos sentimentos e pela formação do caráter, aí incluída a disciplinação da vontade [...]” (EDITORA..., 1953, p. 14).

Na documentação, foi possível vislumbrar essa tendência ao "retorno" da EMC aos bancos escolares, algum tempo antes do golpe militar. Primeiro, porque percebemos a impressão das normas voltadas a este tema nas páginas da Revista ${ }^{11}$. Depois, porque os editores achavam justo publicar o que os membros da Escola Superior de Guerra (ESG) consideravam como indicadores da infiltração comunista no Brasil e de uma possível ameaça de guerra interna, contrária à "boa moral". Percebemos esse tipo de conduta a partir do entendimento do modus operandi da ESG, quanto à divulgação da Doutrina de Segurança Nacional (DSN).

Segundo Martins Filho (2007), ao estudar a cultura militar entre 1959-1964, a DSN fundava-se "[...] na concepção de guerra total em três componentes: a guerra generalizada, a guerra fria e a guerra revolucionária [...]”. No sentido de guerra revolucionária, havia, de acordo com a DSN, uma estratégia políticomilitar que se destinava a vencer "[...] a luta revolucionária ideologicamente dirigida [...]" (MARTINS FILHO, 2007, p. 3-4). Os militares ligados à ESG, de acordo com o autor, formularam uma doutrina própria para combater a guerra revolucionária, e um dos parâmetros dessa formulação foi a idealização de um "[...] programa de alteração das relações civis-militares [...]", como forma de "[...] alcançar a unidade do país no apoio à luta do Exército [...]". A ideia era a de que a população, tal como o Exército, antevisse as etapas do avanço comunista em seu território, no sentido de prevenir-se contra o inimigo (MARTINS FILHO, 2007, p. 11).

Nesse ideário das Forças Armadas, os militares teriam condições de antecipar um ataque preventivo à subversão. Esta era vista pelos militares

11 Portaria $n^{\circ} 419$ de 17/10/1963, dispondo sobre a formação moral e cívica nos estabelecimentos de ensino médio, para se "criar um lastro comum de unidade nacional", por meio do culto aos símbolos pátrios, é um exemplo desse tipo de publicação (EDITORA... 1963a, p. 28). 
como índice de estágio pré-revolucionário, por isso era necessário formular uma ofensiva situada nas "ações de caráter defensivo", das quais a população faria parte. Tais ações seriam centradas na "[...] formação moral e cívica da população, a fim de fornecer-lhe os meios para fazer face à ofensiva da subversão e lutar contra a guerra psicológica”. A ideia era a de elevar o aspecto mecânico desse saber, tal como nos estágios militares, "[...] com a criação de reflexos e atitudes adequadas [...]" (MARTINS FILHO, 2007, p. 16-17).

Um dos sentidos prioritários da DSN era, em princípio, a disseminação institucional da doutrina, para que, depois, a linguagem "árida dos documentos militares" fosse traduzida para o mundo civil. Portanto, de acordo com Martins Filho (2007), a guerra revolucionária saiu dos "currículos militares" e foi anunciada ao mundo civil por meio da mobilização de aparelhos civis de circulação de informações: editoras lançavam livros, divulgavam cartilhas, e jornais apregoavam a ideia de preparo psicológico anticomunista.

O fato é que a Editora do Brasil vai ao encontro dessa perspectiva de "preparo do mundo civil", uma vez que, desde 1961, lançava apelos sobre a entrada e fixação de um "braço" comunista em meio aos estudantes brasileiros. Ao longo dos anos 1960, progressivamente, os textos apresentados no periódico educacional ampliavam o foco do "perigo comunista" e passaram a mostrar que a "infiltração comunista", gradualmente, se transformou em "organizações subversivas", estabelecidas em diversas instituições. Posteriormente, as denominações saltaram para "atos de tumultos e sabotagem" e, por fim, em 1967, foi introduzido nesses textos o termo "terrorismo" 12 . Esse tipo de análise demonstrava o alinhamento dos editores com as designações propostas pelas diretrizes da ESG, principalmente por meio da circulação

12 Isso pode ser exemplificado pelos títulos dos seguintes artigos apresentados em EBSA: "Denúncia de D. Jaime Câmara de conspiração contra a democracia" (EDITORA..., 1961a, p. 12); IV Congresso Internacional de Estudantes, em que foi apresentada uma moção contrária aos "crimes praticados por Fidel Castro", aos estudantes cubanos que divergiam de seu governo (EDITORA..., 1961b, p. 32-36); "Infiltração comunista", artigo que associava os comunistas aos estudantes brasileiros (EDITORA..., 1961c, p. 35); "Comunismo atuante e democracia recuada" (EDITORA..., 1962a, p. 76-77); "Denunciada a comunização do ensino em Brasília" (EDITORA..., 1962b, p. 37); "Os estudantes e a cortina de ferro", artigo que demonstrava a "[...] opressão vivida pelos estudantes no leste europeu invadido pela União Soviética [...]" (EDITORA..., 1963b, p. 66-67); Greves de alunos (EDITORA..., 1963c, p. 72-73). O discurso do Senador Guido Mondim (PRP-RS), "Infiltração comunista”, foi pronunciado no dia 4/12/1962 no Senado Federal. O artigo "Greves de alunos", de autoria de Souza Brasil, foi transcrito do Jornal do Brasil, Rio de Janeiro, 20/9/1963. 
de ideias que instigavam as imagens de país desestabilizado, por ordem de "inimigos" infiltrados nas instituições políticas, sociais e educacionais, seguindo resoluções de sujeitos desprovidos de boa moral.

Foi no período de acirramento das discussões sobre o retorno da disciplina educação moral e cívica para os bancos escolares, que o relacionamento entre os editores e os militares passou de afinidade de ideias para contatos pessoais. Essa ligação se deu, principalmente, a partir da atuação de Victor Mussumeci e Alfredo Gomes que se embrenharam nas discussões sobre o retorno da disciplina EMC para as escolas.

Em 1966, foi anunciada a ida de Victor Mussumeci, representante da Editora do Brasil, à terceira reunião conjunta dos Conselhos de Educação Cívica, promovida pelo Conselho de Educação dentro do Ministério da Educação. Nessa reunião, foi debatido o tema Educação cívica em meio aos representantes dos Conselhos Estaduais de São Paulo (presidido pelo professor Erasmo de Freitas Nuzzi e o padre Lionel Corbeil); Minas Gerais (Emanuel Pontes); Rio Grande do Sul (Irmão José Otão) ${ }^{13}$. Além de Mussumeci, também estiveram na reunião, professores, outros autores de livros didáticos, técnicos e membros do governo. Entre eles, estavam presentes o padre Gabriel Galache, Humberto Grande, padre Orlando Vieira e o marechal Inácio Rolim, membro da Liga de Defesa Nacional ${ }^{14}$.

13 O professor Erasmo Nuzzi foi conselheiro do Conselho Estadual de Educação de São Paulo. O padre Lionel Corbeil foi fundador do Colégio Santa Cruz de São Paulo e teve uma atuação bastante duradoura dentro do Conselho Estadual (1963-1986). O Ir. José Otão foi membro da congregação Marista e um dos fundadores da Faculdade de Ciências Políticas e Econômicas em Porto Alegre, estabelecimento que, no futuro, se tornaria a PUC-RS. Nada foi encontrado sobre Emanuel Pontes.

14 Humberto Grande foi autor de numerosas publicações, tais como: O culto da grandeza (1949), Trabalho, cultura e espírito (1961), Educação cívica das mulheres (1967), A universidade do trabalho e o desajustamento de massas e de classes (1965). Os anos 1950 foram palco de uma ampla divulgação do projeto de universidades para o trabalho. O padre Gabriel Galache era jesuíta, foi diretor das Edições Loyola e autor de livros didático e religioso pela mesma editora. São eles: Brasil: processo e integração Estudos dos problemas brasileiros e Síntese da doutrina social. O padre Orlando Vieira é autor de Pessoa humana no mistério do mundo. Já a Liga de Defesa Nacional é uma "entidade cívico-cultural" fundada por Olavo Bilac em 1916. Ela tem por princípio "robustecer na opinião pública nacional um elevado sentimento de patriotismo" e já foi agraciada com Ordens do Mérito Militar, Naval, Cruz Mérito Educação Cívica e Medalhas Tamandaré (por prestar relevantes serviços para a divulgação das tradições) e D. Pedro II (por prestar importantes serviços no âmbito da defesa civil). 
Nessa reunião, Mussumeci fez a sua intervenção no debate, salientando a ideia de que, no "estudo dos processos para formar o cidadão", era necessária a exigência de quatro tipos de civismo: o patriótico, o institucional, o político e o solidarista. Para Mussumeci, havia fenômenos históricos que estavam alterando as relações entre as pessoas: o crescimento populacional; a crise da educação por "causa de uma vultosa multidão de jovens"; a aceleração do tempo. Tudo isso exigiria uma "efetiva evolução no conceito de solidariedade" (EDITORA..., 1966, p. 2).

Para o professor, naquele momento, o civismo seria fortalecido à medida que fosse associado à ideia de "solidarismo", ação tida como a mais importante manifestação moral a ser ensinada aos jovens, a fim de fortalecer os laços entre eles e a sua comunidade. Segundo o autor, "o binômio pessoacomunidade" seria capaz de responder, positivamente, ao comportamento rebelde dos jovens, já que eles se ocupariam com ações voltadas ao bem-estar das pessoas de forma benevolente (EDITORA..., 1966, p. 4).

Filgueiras (2006) e Oliveira, Guimarães e Bomény (1984) ressaltaram que o "conceito de civismo como expressão da solidariedade", como parâmetro para as futuras incursões do currículo de educação moral, foi definido durante essa reunião. E, como foi possível perceber, a atuação bastante incisiva do representante da Editora do Brasil mereceu um destaque. A partir daí, o termo "solidariedade" faria parte de todos os documentos decisivos para a implantação da disciplina EMC, incidindo, posteriormente, sobre os conteúdos dos livros didáticos ${ }^{15}$. O termo "solidariedade" passou a fazer parte das finalidades da educação moral e cívica no decreto-lei no 869/69. Tornou-se um dos "valores permanentes" dentro dos subsídios para o Currículo e o Programa Básico de EMC proposto pela Comissão Nacional de Moral e Civismo e pelo Conselho Federal de Educação. Nos conteúdos dos livros didáticos, a "solidariedade" estava inserida nas instruções metodológicas para a prática de ensino. Vemos

15 É importante ressaltar que a ideia de "solidariedade" era um dos pensamentos que já "circulava" entre os brasileiros, anteriormente. Primeiro entre os isebianos, em especial Álvaro Vieira Pinto, que via no "trabalho" um ponto de solidariedade entre as diversas classes sociais que buscavam o desenvolvimento do Brasil (FRANCO, 1978). Dentro do próprio movimento estudantil, especialmente na Ação Popular, corrente saída da Juventude Universitária Católica (JUC). Essa corrente juvenil via a solidariedade como um dos elementos agregadores entre os estudantes ao povo, "[...] grupo cego a ser guiado rumo às transformações sociais [...]” (FÁVERO, 1994, p. 33). 
que esse termo, diante de várias discussões em torno de seu significado, remodelado, foi tornado um princípio ético a ser exaltado, um dos motores dos discursos da editora, nos anos 1960.

A solidariedade humana como valor essencial para a unidade da pátria também aparecia nos discursos do Gal. Moacir Araújo Lopes ${ }^{16}$. O Gal. Araújo Lopes seria um dos tradutores dessa ideia de preparo do mundo civil, tanto na Comissão Nacional de Moral e Civismo (CNMC), quanto por meio das conferências proferidas em locais específicos, como o Círculo Militar de São Paulo. De acordo com Filgueiras (2006, p. 59), esse militar foi um dos principais idealizadores do anteprojeto de lei da disciplina educação moral e cívica. Como veremos, Araújo Lopes passou a ter relações com os editores de livros didáticos em geral e com os membros da Editora do Brasil, em particular, seja por meio da coalização de ideias, seja pessoalmente.

Como indicou Filgueiras (2006), além de a Editora do Brasil ter sido a editora que mais publicou livros didáticos de EMC, os seus membros divulgavam que os livros de EMC editados "[...] achavam-se rigorosamente de acordo com o programa oficial de Educação Moral e Cívica”. Esses livros possuíam "praticamente os mesmos temas do programa curricular" (FILGUEIRAS, 2006, p. 116). Nesse sentido, a Editora do Brasil deixava evidente que o conteúdo de suas publicações de EMC não só era preenchido pelas ideias de seus editores, mas tentava criar uma sintonia ideológica entre aquilo que eles acreditavam e o que passou a ser determinado pelos pensadores da ESG.

O livro de Mussumeci, Costa e Moschini, por exemplo, usou o conceito de segurança nacional do general Moacir Araújo Lopes como elemento fundamental para o entendimento de moral e civismo. O livro justificou a ação do governo de então (ações políticas, econômicas, psicossociais e militares) como garantia para a "[...] consecução ou manutenção dos objetivos nacionais, em face dos antagonismos existentes [...]" (FILGUEIRAS, 2006, p. 160) ${ }^{17}$.

$16 \mathrm{O}$ general deu aula nas escolas de comando e Estado-Maior, tinha conhecimento estratégico-militar dentro da ESG, foi membro da Associação de Diplomados da Escola Superior de Guerra, especialista de "Liderança na guerra revolucionária" (MARTINS FILHO, 2007, p. 18).

17 Fernando N. Moschini era padre e esteve ligado à Federação do Comércio de São Paulo. Participou da campanha de educação cívica realizado pela União Cívica Feminina em 1964, sendo conferencista de diversos estudos sobre os problemas nacionais promovidos por aquela entidade (FILGUEIRAS, 2006, p. 103). 
Dando continuidade a sua preocupação com a moral e o civismo, o professor Alfredo Gomes, em janeiro de 1969, passou a publicar a "peregrinação cívica" do Gal. Araújo Lopes, que dava palestras sobre esse assunto por todo o Brasil. Também foi por intermédio do mesmo professor que as palavras do Gal. José Nogueira Paes passaram a ser publicadas pela editora. Uma das publicações tratava da conferência proferida no Círculo Militar de São Paulo sobre "O Serviço Militar e as Responsabilidades das Autoridades e das Lideranças Civis” (EDITORA..., 1969, p. 3$)^{18}$.

Alfredo Gomes não escondia e se comprazia com os contatos pessoais adquiridos durante esse período, ele mesmo autor do livro Numes tutelares: alameda cívica Mal. Maurício José Cardoso, que foi publicado em 1971. Dentro do Círculo Militar, o redator pôde manter relação com esses conferencistas vindos da caserna, conservando um contato, senão de amizade, no mínimo mantida pela afinidade de ideias. Gomes relata, por exemplo, que recebeu um exemplar do anteprojeto de lei sobre a educação moral e cívica elaborado em 31 de julho de 1968, em "caráter reservado", das mãos do próprio Gal. Araújo Lopes. Diz o autor que ambos tiveram lampejos de melancolia diante da ausência da EMC nos currículos (EDITORA..., 1969, p. 2-3) ${ }^{19}$.

Esse caráter de "antecipação" da editora, em relação às discussões sobre a reintrodução de EMC nos currículos escolares, e o "caráter reservado" das transações pessoais nos conduzem a três vestígios sobre as práticas efetuadas pelos editores: 1) de que eles conseguiam, com antecedência, compreender as normas que seriam aplicadas ao mercado do livro didático, e, por isso, conseguiam se organizar previamente para atender à demanda das escolas; 2) essas informações repassadas, às vezes, "reservadamente", dão um sentido de estreitamento de laços, criando um aspecto de cumplicidade entre a editora e um representante do governo instituído; 3) os editores foram partícipes dos fóruns de discussão organizados pelos dirigentes da CNMC, nas decisões que interferiram no currículo das escolas, na produção de livros, nos conteúdos

18 O Gal. José Nogueira Paes era diretor do serviço militar, encarregado por coordenar e controlar todas as atividades ligadas à prestação do serviço militar no país.

19 De acordo com Cunha (2006): "Nesse período, a EMC ora foi incluída no currículo, ora foi dele suprimida: presente na 'lei' orgânica do ensino secundário (1942) até o fim do Estado Novo; ausente na República Populista, para retornar com toda a força em 1969 (Decreto-Lei 869), sendo mais uma vez suprimida em 1993 (Lei 8.663)" (CUNHA, 2006, p. 5087). 
aplicados nas disciplinas e, por isso, colocavam-se em um local privilegiado de poder. Local em que, de acordo com Mathias (2004, p. 192), estava concentrado "o maior número de militares no período", ou seja, nos fóruns de discussão e nas comissões de planejamento.

De acordo com Mathias (2004), os militares fizeram uso das comissões, fóruns de discussão e grupos de trabalho como ambientes preferenciais para a tomada de decisões, no sentido de promoção das reformas voltadas ao "Brasil grande". Militarização aqui entendida como a presença física de membros militares nesses órgãos de decisões ${ }^{20}$. No caso da educação, os militares pareciam preferir essa via de trabalho, pois tentavam se desviar do poder dos órgãos executores e planejadores constituídos, na tentativa de esvaziar os poderes advindos dos burocratas de carreira, pois era basilar naquele momento ter o controle das decisões. Assim, a ideia era desviar-se das discussões feitas no Ministério da Educação e, principalmente, no Conselho Federal da Educação (CFE), já que este órgão, mesmo que normativo, estava investido de poderes amplos, de acordo com a LDB/1961.

Aqui, não se está falando que essa tentativa de desvio acontecia por conta de uma total oposição dos militares às delegações do CFE. Como demonstrou Martins (2002, p. 69), apesar de esse órgão de natureza "técnica", "normativa" e "decisória" ser um "um dos mais altos patamares na hierarquia da administração pública", funcionava com poderes limitados, no momento em que se contrapunha às decisões do governo. Segundo a pesquisadora, o papel de "elaborador de medidas legitimadoras do governo ao qual estava ligado eram muito fortes" e, por conta disso, o "seu papel foi tão determinante na reforma educacional da ditadura militar", não constituindo um "poder paralelo" (MARTINS, 2002, p. 84-85).

Ao que parece, se houve um "poder paralelo" atuando sobre a educação brasileira, ele não estava no CFE, e sim, dentro dos ambientes das comissões e fóruns de debate, já que ali, com a presença dos militares, foi possível a

20 A extensão universitária no Brasil, por exemplo, foi amplamente discutida em comissões e fóruns. Os debates feitos em comissões e fóruns, a partir da associação civil-militar, criaram, por exemplo: o Centro Rural Universitário de Treinamento e Ação Comunitária (Crutac); o Projeto Rondon; e o Projeto Mauá (1966). A Comissão Meira Mattos (1967) e o fórum "A educação que nos convém" (1967), iniciativa conjunta do governo, da PUC-RJ e do Jockey Clube do Brasil, também nos servem de exemplos para mostrar os trabalhos feitos por associações civis militares (MATHIAS, 2004, p. 165). 
ampliação do rol de alianças e influências, feitas a partir da vigência de diversos tipos de relações pessoais (clientelismo, fisiologismo, nepotismo). Por um lado, tentava-se burlar o poder de um órgão governamental. Por outro, o funcionamento das comissões apresentava uma flexibilidade que dava, tanto quanto possível, anonimato às ações de grupos civis, empresariais, que participavam de ações combinadas com os militares responsáveis pela educação do país.

Os grupos mantidos nas comissões podiam tanto se desviar do "notório saber" dos membros do CFE, quanto ter o sinal de que muito dificilmente o órgão faria contraposição direta aos interesses dos militares participantes dos debates educacionais ${ }^{21}$. Havia, inclusive, a possibilidade de os debates feitos nas comissões irem parar no CFE, buscando constranger os pareceres produzidos pelo conselho. Essas agências, com as suas diferentes formas de atuar, acabam explicando os duelos e jogos de força entre os membros do CFE e os componentes da CNMC apontados por Filgueiras (2006). A pesquisadora nos diz que os dois grupos tinham divergências e eram "diversas" as "críticas públicas" feitas pelo Gal. Araújo Lopes ao Conselho Federal, por conta da relutância desse órgão em instituir a EMC como disciplina nas escolas (FILGUEIRAS, 2006, p. 62).

Dentro das comissões, pudemos perceber a articulação de diversos grupos interessados no retorno da disciplina EMC: havia professores que eram representantes de instituições de ensino, editores de livros didáticos, membros da Igreja, também professores e autores etc. Esses sujeitos estavam articulados aos movimentos empreendidos por militares, que atuavam mais diretamente na difusão de conhecimentos produzidos dentro da ESG, conhecimentos esses que passaram a ser difundidos pelas produções editoriais na forma de textos e conteúdos didáticos. De certa forma, podemos entender os debates feitos pela CNMC como resoluções de um cartel, já que vemos ali acordos implícitos e explícitos entre editoras concorrentes, demarcando o conteúdo de uma disciplina escolar e o currículo que seria estabelecido para o trabalho escolar. Ao mesmo tempo, determinando, em ação coordenada, o aspecto material e o valor que teria a mercadoria "livro".

21 Martins (2002, p. 67) demonstrou que o governo militar, posteriormente, alterou as funções do órgão, de forma a "interferir em suas ações". 


\section{A Editora do Brasil nos anos 1970: a consolidação de uma vontade}

Segundo Filgueiras (2006, p. 97), a Editora do Brasil foi uma das editoras que mais se destacou no período militar ${ }^{22}$. Já para Cassiano (2003), foi uma das editoras que deu um salto quantitativo de vendas de livros didáticos e infantis, por conta da expansão da rede de ensino e das modificações propostas pela LDB (Lei 4.024 de 20/12/1961) e a Lei no 5692 (11/08/1971). De acordo com Cassiano (2003, p. 40), mais de 60 editoras figuraram entre produtoras de livros didáticos naquele período, mas, além da Companhia Editora Nacional, que já dominava o mercado desde 1940, a Editora do Brasil passou a figurar como uma das mais importantes editoras do país.

Cassiano (2003, p. 40) estreitou essa perspectiva e atribui essa expansão ao desenvolvimento da produção de livros nos anos 1960, como resultado da associação entre as editoras e os programas governamentais, tais como a Comissão do Livro Técnico e do Livro Didático (COLTED), que verteu investimentos na ordem de US\$ 9 milhões. Isso evidenciou a satisfação da Editora do Brasil com o convênio entre o Ministério da Educação e a United States Agency for Internacional Development (USAID) e, mais precisamente, com o acordo de $\mathrm{n}^{\circ}$ 9, de 6 de janeiro de 1967, cujo teor estabelecia, exatamente, a cooperação para as publicações técnicas, científicas e educacionais.

Munakata (2008) explicou que esse convênio, caracterizado por seu "gigantismo", pretendia estimular a expansão da indústria editorial de livros técnicos e didáticos, assinalando que, segundo os proponentes, essa expansão do mercado resultaria na diminuição do custo do livro. De acordo com o autor, esse acontecimento provocou "alvoroço" nos meios editoriais. Entre as editoras com parcerias regulares com o Estado no processo de edição, figurava a Editora do Brasil, com 14\% dos livros editados (MUNAKATA, 2008 , p. 3-5 $)^{23}$.

22 Filgueiras (2006) pesquisou 62 livros de EMC do período. A pesquisadora indicou que 9 deles foram publicados pela Editora do Brasil e fizeram parte da lista de livros aprovados pela Comissão Nacional de Moral e Civismo (CNMC). Victor Mussumeci, com o seu livro de educação moral e cívica para o ginásio, alcançou a marca de 91 edições.

23 As outras editoras eram: FTD (10\%), Abril (8\%), IBEP (7\%), Ao Livro Técnico (6\%) e Tabajara (5\%) (OLIVEIRA; GUIMARÃES; BOMÉNY, 1984). 
Percebe-se, portanto, que o salto quantitativo da editora em questão tinha relação direta tanto com os contatos feitos ao longo do movimento de retorno da disciplina de EMC, quanto com as ações governamentais de largo espectro que tinham o foco voltado para a expansão do livro didático no país.

Os membros da Editora do Brasil, entre outros, foram sujeitos beneficiados pela política de uma comissão que tinha por objetivo “[...] tornar disponíveis cerca de 51 milhões de livros (técnicos e didáticos) [...]" pela rede editorial e de distribuição já instalada (MUNAKATA, 2008, p. 3). A introdução da disciplina EMC nos currículos parece ter incrementado o rendimento da editora, mas, como podemos ver, o alvoroço causado pelos acordos com a USAID injetou ânimo na produção de vários outros tipos de livros.

No dia 22 de janeiro de 1971, o jornal O Estado de S. Paulo, em sua página 9, apresentou um anúncio de página inteira, expressando a inauguração do parque gráfico da Editora do Brasil em Guarulhos. Dizia o anúncio: "Viu, Gutemberg? Inauguramos o maior parque industrial do livro no país".

Em concomitância a esse anúncio, EBSA publicou os dados sobre o novo parque gráfico fixado na grande São Paulo. A nova área industrial tinha 16 mil metros quadrados de área em concreto armado, com área-depósito de 2 mil metros quadrados, com a capacidade de produzir 50 mil livros por dia e um milhão de livros por mês. Dispondo de "[...] off-set, fotolitos e impressoras, a serviço de 600 autores, 100 desenhistas, 240 técnicos e centenas de educadores [...]", o parque gráfico, segundo eles, era um dos "maiores da América Latina" (EDITORA..., 1971).

O triênio 1971 - 1972 - 1973 pode ser considerado o período áureo da Editora do Brasil. Com relação aos livros produzidos, foi possível constatar, por exemplo, que, entre 1970 e 1975, dos 117 registros de documentos apresentados pela editora no $3^{\circ}$ Oficial de Registros de Títulos e Documentos de São Paulo, 80 deles eram de contratos de edição de livros. Ficou evidente, na documentação desse período, que os tempos de humildade haviam ficado no passado (EDITORA..., 1971, p. 5).

A Editora do Brasil manteve-se fiel ao seu princípio de defensora das causas da moral e do civismo. Para fazer a divulgação do I Simpósio de Educação Moral e Cívica, Gomes, em 1975, voltava a reiterar que "os valores morais da nacionalidade", "a unidade nacional", o "culto à Pátria" etc. deveriam ser respeitados. Isso, segundo o cronista, seguindo "a concepção espiritualista da vida" e a "concepção democrática do Estado" (EDITORA..., 1975, p. 9-12). 
Em fevereiro de 1976, Geraldo Mantedônio Bezerra de Menezes, presidente da CNMC, por ofício, saudou a crônica feita meses antes. Sobre a revista da editora, diz o presidente-conselheiro: "[...] são os nossos votos que V. Sa. e a EBSA, sob a orientação sadia da Editora, continuem a prestar sua valiosa colaboração à causa da moral e do civismo, a que tanto podem servir os meios assistemáticos da educação [...]" (EDITORA..., 1976, p. 4). E assim continuou sendo feito até 1980, quando Otto Costa, o mais recente redator da editora, transcreveu trechos do livro Educação moral e cívica de sua autoria, para dizer que a estrutura constitucional do Brasil girava em torno das seguintes "instituições máximas": a "Família, a Escola, a Justiça, a Igreja, as Forças Armadas, a Pátria” (EDITORA..., 1980, p. 6).

\section{Considerações finais: a Editora do Brasil - EBSA S/A (1961-1980)}

A editora bem utilizou a demanda ofertada pelos colégios privados, especialmente os confessionais, que estavam em um período de ampla expansão nos anos 1950-1960 (CARVALHO, 2003, p. 40). Foi uma editora familiar que cresceu, primeiro produzindo livros didáticos, atendendo a uma demanda dada pela expansão das escolas brasileiras. Posteriormente, nos anos 1960, se beneficiou com o aumento do mercado livreiro feito nos termos do acordo MEC-USAID, em 1967.

Os editores eram patrões que não se esqueciam dos $10 \%$ de gratificação anual para os funcionários (ata da reunião ordinária de setembro de 1946). Como profissionais liberais, aproveitaram as oportunidades mercadológicas de uma época, apresentaram tino comercial e se lançaram ao mercado editorial, amparados pela ideia do self-made man. Esta ideia pode ser muito bem representada por uma transação de crédito, datada de novembro de 1971, feita entre as famílias Costa e Netto e o Banco do Estado de São Paulo (Banespa). Dois anos antes da inauguração do parque gráfico, vários imóveis da família Costa e Netto (o prédio sede da editora em São Paulo, um "prédio residencial", dois terrenos) foram dados para a garantia de dívida ao banco estadual e este a repassou ao Banco Nacional de Desenvolvimento Econômico (BNDE). É possível inferir, portanto, que os membros dessa editora familiar se lançaram em um grande risco financeiro para que, enfim, o 
seu empreendimento fosse levado a cabo. Eles também souberam interpretar os movimentos sociais internos ao mercado de livros, usando-os de forma a alçar a si mesmos entre as principais empresas do gênero.

Nos anos 1960, período de competitividade empresarial, os diretores da Editora do Brasil passaram a não se valer somente da aceitação dos seus produtos e do marketing proposto para eles. Isso foi somado a outras possibilidades de arrolamento de capital e elevação do status da empresa, tais como: a obtenção de vantagens no campo da produção do conhecimento; benefícios das políticas governamentais; e liberdade na promoção, para as escolas de ensino médio do país, de valores culturais que os atrelavam ao regime instituído em 1964. Isso demonstrou que houve uma ampliação do inventário de possibilidades de crescimento da marca, mas também evidenciou um esforço, direto e indireto, em se manter ao lado do regime militar.

Os editores admitiam que a editora estava "[...] contribuindo para o engrandecimento do Estado e o bem-estar social da sua gente, marchando paralela ao Governo". Segundo os editores, “[...] só assim, com essa colaboração lado a lado [...]" seria possível avançar para o "[...] futuro com segurança, com firmeza [...]” (EDITORA..., 1972). Estar paralelo ao governo significava lutar, apenas, contra uma "possível ameaça de guerra interna por conta da invasão comunista”, ideia planejada na ESG, ideia que os seus materiais didáticos reverberaram com ênfase. Registramos aqui os debates e os planejamentos instituídos pela CNMC, nos quais, os membros da editora tiveram atuação destacada. $\mathrm{Na}$ diversidade do tecido social, os editores souberam manter relações sociais que foram usadas na defesa de interesses da empresa.

Dessa forma, pensando nas relações estabelecidas entre grupos civis e militares nesses ambientes de debates, podemos dizer que as políticas públicas também foram resultado de interesses particulares, e não representavam somente os anseios modernizadores de uma parcela dos militares. Existiam demandas difusas, da parte da sociedade, que foram intercaladas nesse jogo de alianças. Os diretores da Editora do Brasil se aproximaram de facções decisivas para o seu negócio, de forma a interceder nas políticas voltadas à produção de livros didáticos, ao ponto de ter os seus editores associados com representantes de outras editoras e entidades civis, opinando nas reformulações curriculares. 


\section{Fontes}

$4^{\circ}$ Oficial de Registro de Títulos e Documentos. Carta da Indústria Gráfica Siqueira à Editora do Brasil S/A. São Paulo, 1960.

$4^{\circ}$ Registro de Títulos de Documentos. Carta da Delegacia Litúrgica de São Paulo. São Paulo, 1971. Microfilme no 1223691.

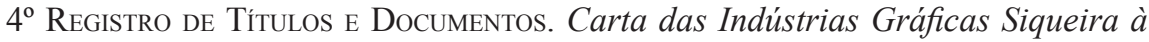
Editora do Brasil S/A. Microfilme nº 245222/60. São Paulo, 1971.

$4^{\circ}$ Registro de Títulos e Documentos. Carta de Ismael Andrade Cunha à Editora do Brasil S/A. Microfilme n ${ }^{\circ} 116000$. São Paulo, 1971.

BRASIL. Decreto de Lei no 869, de 12 de setembro de 1969. Dispõe sobre a inclusão da Educação Moral e Cívica como disciplina obrigatória, nas escolas de todos os graus e modalidades, dos sistemas de ensino no país e dá outras providências. Diário Oficial da República Federativa do Brasil, Brasília, DF, set. 1969.

CÂmara, Jaime. O cardeal D. Jaime Câmara. Revista da Editora do Brasil, São Paulo, p. 39, 1961.

Costa, Otto. Trinta anos. Revista da Editora do Brasil S/A, São Paulo, p. 3-5, 1977.

Editora do Brasil S/A. Problemas educacionais. Revista da Editora do Brasil S/A, São Paulo, p. 1-4, 1953.

Editora do Brasil S/A. Como EBSA é recebida. Revista da Editora do Brasil S/A, São Paulo, p. 26-28, 1951.

Editora do Brasil S/A. No limiar da segunda década. Revista da Editora do Brasil S/A, São Paulo, p. 1-4, 1957.

Editora do Brasil S/A. A sentença das urnas. Revista da Editora do Brasil S/A, São Paulo, p. 1-4, 1960.

Editora do Brasil S/A. O cardeal D. Jaime Câmara denuncia traição à Igreja. Revista da Editora do Brasil S/A, São Paulo, p. 9, 1961a.

Editora do Brasil S/A. IV Congresso Internacional dos Estudantes. Revista da Editora do Brasil S/A, São Paulo, p. 32-36, 1961 b.

Editora do Brasil S/A. Infiltração comunista. Revista da Editora do Brasil S/A, São Paulo, p. 35-36, 1961c. 
Editora do Brasil S/A. Comunismo atuante e democracia recuada. Revista da Editora do Brasil S/A, São Paulo, p. 76-77, 1962a.

Editora do Brasil S/A. Denunciada a comunização do ensino em Brasília. Revista da Editora do Brasil S/A, São Paulo, p. 37, 1962b.

Editora do Brasil S/A. Portaria $\mathrm{n}^{\circ}$ 419. Formação moral e cívica dos estabelecimentos de ensino médio. Revista da Editora do Brasil S/A, São Paulo, p. $28,1963 \mathrm{a}$

Editora do BRAsil S/A. Estudantes estrangeiros atrás da "cortina de ferro". Revista da Editora do Brasil S/A, São Paulo, p. 66-67, 1963 b.

Editora do Brasil S/A. Greve de alunos. Revista da Editora do Brasil S/A, São Paulo, p. 72-74, 1963c.

Editora do Brasil S/A. O Presidente e os estudantes. Revista da Editora do Brasil $S / A$, São Paulo, p. 1-2, 1964.

Editora do Brasil S/A. A Educação Cívica. Revista da Editora do Brasil S/A, São Paulo, p. 1-6, 1966.

Editora do Brasil S/A. Aniversário. Revista da Editora do Brasil S/A, São Paulo, p. 1-2, 1969.

Editora do Brasil S/A. Ano de renovação. Revista da Editora do Brasil S/A, São Paulo, p. 1-6, 1971.

Editora do Brasil S/A. Paz na terra. Revista da Editora do Brasil S/A, São Paulo, p. 1-8, 1972.

Editora do Brasil S/A. Educação moral e cívica. Revista da Editora do Brasil S/A, São Paulo, p. 3-12, 1975.

Editora do Brasil S/A. Educação moral e cívica. Revista da Editora do Brasil S/A, São Paulo, p. 3-4, 1976.

Editora do Brasil S/A. Inauguração da sede própria da Editora do Brasil S/A em Brasília. Revista da Editora do Brasil S/A, São Paulo, 1978.

Editora Do BRAsil S/A. Vinculação de nossa educação ao espírito da Constituição. Revista da Editora do Brasil S/A, São Paulo, p. 3-16, 1980.

Ferraz, Esther de Figueiredo. Discurso de posse de Esther de Figueiredo Ferraz. Revista Documenta, Brasília, 1970. 
Gomes, Alfredo. Educação moral e cívica. Revista da Editora do Brasil S/A, São Paulo, p. 1-6, 1969.

Concílio vaticano II. Declaração Gravissimum Educationis sobre a educação cristã. Disponível em: <http://www.vatican.va/archive/hist_councils/ii_vatican council/documents/vat-ii_decl_19651028_gravissimum-educationis_po.html > Acesso em: 30 ago. 2009.

Junta Comercial de São Paulo. Ficha cadastral de breve relato. Nire matriz: 3530003767 7. São Paulo, 1943.

Junta Comercial de São Paulo. Ata da segunda assembléia geral ordinária da Editora do Brasil S/A, $n^{\circ}$ 19134. São Paulo, 1945.

Junta Comercial do Estado de São Paulo. Ata da terceira assembléia geral da Editora do Brasil S/A, $n^{\circ} 29825$. São Paulo, 1946.

Junta Comercial do Estado de São Paulo. Ata da quarta assembléia geral da Editora do Brasil S/A, $n^{\circ}$ 34412. São Paulo, 1947.

Junta Comercial do Estado de São Paulo. Ata da vigésima primeira assembléia Geral da Editora do Brasil S/A, $n^{\circ}$ 265730. São Paulo, 1964.

Junta Comercial do Estado de São Paulo. Alteração dos Estatutos da Editora do Brasil S/A - Ata da vigésima terceira Assembléia Geral, $n^{\circ}$ 411166. São Paulo, 1969.

Junta Comercial de São Paulo. Ficha cadastral de breve relato. Nire matriz: 3530003767 7. São Paulo, 2007.

Mussumeci, Victor. Organização social e política brasileira. 23. ed. São Paulo: Editora do Brasil, 1963.

\section{Referências}

Almieri, Tatiana. Guinada para a direita - Da visão liberal ao conservadorismo. In: LeItURAs da história. São Paulo: Editora Escala, 2007. p. 26-43.

Cassiano, Célia Cristina de Figueiredo. Circulação do livro didático: Entre práticas e prescrições - Políticas públicas, editoras, escolas e o professor na seleção do livro escolar. 2003. Dissertação (Mestrado em Educação) - Pontifícia Universidade Católica de São Paulo, São Paulo, 2003. 
Carvalho, João do Prado Ferraz. A Campanha de Defesa da escola Pública em São Paulo (1960-1961). 2003. Tese (Doutorado em Educação)-Pontifícia Universidade Católica de São Paulo, São Paulo, 2003.

Cunha, Luiz Antônio. Sintonia oscilante: religião e educação moral e cívica no Brasil (1931-1997). Percursos e desafios da pesquisa em história da educação. In: Congresso Luso Brasileiro de História da Educação - COLUBHe, 2006, Uberlândia. Anais eletrônicos.... Disponível em: <http://www.faced.ufu.br/ colubhe06/anais/arquivos/464LuizAntonioCunha.pdf>. Acesso em: 15 jan. 2009, 20:30.

FÁvero, Maria de Lourdes Albuquerque. UNE nos tempos do autoritarismo. Rio de Janeiro: Editora da UFRJ, 1994.

Filgueiras, Juliana Miranda. Educação moral e civica e a sua produção didática: 1969-1993. 2006. Dissertação (Mestrado em Educação) - Pontifícia Universidade Católica de São Paulo, São Paulo, 2006.

Franco, Maria Sylvia Carvalho. O tempo das ilusões. In: Chaú, Marilena; Franco, Maria Sylvia Carvalho. Ideologia e mobilização popular. Rio de Janeiro: Editora Paz e Terra, 1978. p. 151-209.

Hallewell, Laurence. Octalles Marcondes Ferreira. In: Hallewell, Laurence. $O$ livro no Brasil. São Paulo: T. A. Queiroz: Editora da Universidade de São Paulo, 1985.

Martins, Maria do Carmo. A história prescrita e disciplinada nos currículos escolares: quem legitima esses saberes? Bragança Paulista: Edusf, 2002.

Martins Filho, João Roberto. A educação dos golpistas: cultura militar, influência francesa e golpe de 1964. UFSCar, 2007. Disponível em: <http:// www2.ufscar.br/ uploads/forumgolpistas.doc>. Acesso em: jul. 2008.

Mathias, Suzeley Kalil. A militarização da burocracia: a participação militar na administração federal das comunicações e da educação, 1963-1990. São Paulo: Editora Unesp, 2004.

Munakata, Kazumi. O gigantismo da comissão do livro técnico e do livro didático. 2008. No prelo.

Neves, Edna Rosele da Conceição. Uma trajetória pela história da produção editorial brasileira: O livro de matemática - autores e editoras. 2005. Dissertação 
(Mestrado em Educação Matemática) - Pontifícia Universidade Católica de São Paulo, São Paulo, 2005.

Oliveira, João Batista Araujo; Guimarães, Sonia Dantas Pinto; Bomény, Helena Maria Bousquet. A política dos livros didáticos. Campinas: Editora da Universidade Estadual de Campinas, 1984.

Silva, Claudia Panizzolo Batista da. Atualizando pedagogias para o ensino médio: um estudo sobre a Revista Atualidades Pedagógicas (1950-1962). 2001. Dissertação (Mestrado em Educação) - Pontifícia Universidade Católica de São Paulo, São Paulo, 2001.

Silva, José Ramiro Alves da. A legitimação da ordem autoritária: Gustavo Corção nas páginas do Correio do Povo (1964-1969). 2004. Dissertação (Mestrado em História) - Pontifícia Universidade Católica do Rio Grandedo Sul, Porto Alegre, 2004.

Endereço para correspondência: Katya Mitsuko Zuquim Braghini Programa de Estudos Pós-Graduados em Educação: História, Política, Sociedade (EHPS) Pontifícia Universidade Católica de São Paulo Rua Ministro Godói, 969, $4^{\circ}$ andar, Bloco A, Sala 4E-19

Perdizes

São Paulo - SP CEP: 05015-901

E-mail: katya.braghini@yahoo.com.br

Recebido em: 23 abr. 2012 Aprovado em: 27 jul. 2012 